\title{
Monitoring and Evaluation of the Lateral Stability of CWR Track
}

\author{
Vitaly Atapin (1) - Alexey Bondarenko (i) - Mykola Sysyn (ㄱ) \\ Dimitri Grün
}

Submitted: 17 August 2021 / in revised form: 8 November 2021/Accepted: 17 November 2021/Published online: 30 December 2021

(C) The Author(s) 2021

\begin{abstract}
Continuous welded rail (CWR) track has great advantages of low-cost maintenance, environmental influence, and ride comfort. However, the CWR track is subjected to the longitudinal stresses in rails due to temperature influence as well the inhomogeneous stress accumulation due to train loadings. The stresses cause the accelerated track lateral irregularity accumulation that without timely maintenance can cause track buckling. The present paper present a method of the CWR track lateral stability estimation during its lifecycle using the track geometry monitoring information from the track measurement cars. The methods proposes a systematic approach of track stability evaluation based on multiple criteria of track stability evaluation. It takes into account the lateral resistance of the track, actual temperatures, and the lateral geometry condition of the track. The presented case study of a half-year track geometry monitoring and the track stability evaluation in a track curve shows the practical possibility of the recent detection of the track sections with low lateral stability and buckling prevention.
\end{abstract}

Keywords CWR track · Monitoring ·

Lateral track stability - Lateral track curvature .

Temperature equivalent .

Lateral track irregularities accumulation

V. Atapin - A. Bondarenko

SPC INFOTRANS, Polevaya Str. 47, Samara, Russia 443001

M. Sysyn $(\bowtie) \cdot$ D. Grün

Institute of Railway Systems and Public Transport, Technical

University of Dresden, Hettnerstraße 3/353, 01069 Dresden,

Germany

e-mail: mykola.sysyn@tu-dresden.de

\section{Introduction}

The construction of a joint-free CWR track is currently predominant on the world's railway network. In various countries, the joint-free track operates in a wide variety of natural, climatic, and operational conditions. All highspeed and high-speed train traffic is realized on the CWR track. In addition, the CWR is the most preferable for ensuring smooth and comfortable transportation of passengers and cargo. At the same time, it is necessary to take into account the main feature of this design - the presence of temperature stresses in the rails, which affect the stability parameters during operation.

Violations committed during the construction of a CWR track, as well as in the process of current maintenance, together with the impact of train load and natural and climatic factors, create conditions for the growth of temperature stresses in rails and changes in the temperature regime of their operation. The combination of these factors, in the end, can lead to an imbalance of the forces holding the rail-sleeper grid and shifting it, i.e., the shift of the track that can cause track buckling and derailment.

A key role in the buckling prevention is played by ensuring the lateral load-bearing stability of the CWR track from shift by conducting regular monitoring of the temperature mode of operation of rails [1-3], the condition of which is influenced by a number of factors [4]. The most obvious factors that shift the rail-sleeper grid include:

The condition of the rails in the plan (irregularities in the plan);

The longitudinal shift of the rails.

The aim of the present study is a development of the method for determining the conditions and indicators of the 
lateral stability of a CWR track in the plan based on the track lateral geometry monitoring information. The method evaluating the condition of the rail of a CWR track in the plan on the basis of indicators characterizing the temperature-stress mode of their operation.

\section{Review of the Current Studies}

The problem of CWR track stability and its monitoring is considered in many recent studies. A detailed analysis of the track stability estimation methods for low radius curves is presented in the studies [5-7]. In the paper, [5] presents a review and analysis of the current literature to be able to choose a practical value for lateral resistance of monoblock concrete ties. A minimum radius labeled as the threshold radius is determined when a ballasted, CWR curved track would not move under the action of thermal load in an unloaded track. A formula is derived in this paper to determine the threshold value. A 3D numerical model for simulating the track buckling by considering it as a continuous beam was developed in [8]. The methodology is presented allowing the calculation of the safe temperature, and analytical results are also derived for comparison with the numerical results. The paper [9] presents a solution for the antisymmetric post-buckling of such members when restrained by a nonlinear foundation that includes softening effects. The results of the analysis show that the postbuckling configuration of the column changes from a lengthwise periodic mode at the initial stages of loading to an isolated sinusoidal mode at the later stages of postbuckling, which represents a localization in the postbuckling range. A finite element models were developed in the study [10] with which the interaction of continuously welded rail track and steel railway bridges was simulated. It was provided the technical solutions of track structures on bridges with ballasted track, so rail expansion joints can be omitted. A definition for variations in neutral and float temperatures in CWR is proposed in [11] as a function of media temperature and lateral track stiffness or lateral displacement of the track. The method was proved by a case study with field tests and computer modeling. Another studies of the authors [12-14] were directed on numerical investigating the effects of the vertical load, track irregularity, its stiffness, and lateral resistance of sleepers on the track stability. The finite element method (FEM) and discrete element method (DEM) were used for the numerical simulation. The findings of the studies are the quantitative results of the factors influence. The papers $[15,16]$ present the experimental and theoretical studies of resistance characteristics of composite sleeper and concrete sleeper in ballast bed as well as the influence of polyurethane gluing the ballasted track in a high-speed railway. The results indicate the significant increase of the resistance for the studied cases. A method for accurately determining the longitudinal additional force in CWR on bridges via hetero-cladding fiber Bragg grating (HC-FBG) sensors was proposed in the paper [17]. The methods are based on the measurement of wavelength differences of two FBGs with the change of applied longitudinal force. The laboratory tests demonstrate high linearity and sensitivity to the longitudinal force measurement. A parametric finite element model of CWR track is presented in [18] for studying its thermal buckling and post-buckling behavior. It was found that the minimum buckling temperature depends only on the limit lateral resistance, whereas a high value of the initial stiffness can lead to overestimation of the maximum buckling temperature, also taking into account the decrease in the maximum buckling temperature due to an increase in the railway-traffic-induced defect amplitude. The paper [19] presents an investigation of the lateral buckling and post-buckling response of railway tracks under thermal loading that includes the restraining effect of the ballast in the longitudinal and lateral directions. The buckling analysis shows that firstorder symmetric and antisymmetric modes may govern the buckling. The effects of the lateral and longitudinal ballast resistance are quantified, and it is shown that the lateral resistance is predominant when compared with the longitudinal resistance. A full-scale test model with a distinct loading system is developed in the study [20] to analyze the dynamic change process of ballast beds under cyclic longitudinal reciprocated loading. The analysis shows that the ballast resistance-displacement curves under cyclic loading are a set of closed hysteretic curves, indicating energy consumption. The cyclic softening of a granular ballast bed is dependent on the dynamic disturbance amplitude - the higher the dynamic disturbance amplitude, the more severe is the cyclic softening. The paper [21] presents a CWR monitoring approach for rail buckle early warning detection using in-service instrumented revenue vehicle. The approach looks for step changes in the curvature as seen by the bogie, using sensors fitted to Instrumented Revenue Vehicles designed and successfully installed by Institute of Railway Technology at Monash University. A comprehensive review of the methods and the software tools for the 3D modeling and nonlinear analysis stability of CWR tracks is presented in [22]. The methods are analyzed and compared. A method for measuring longitudinal rail stress using resistance strain gauges is presented in the study [23]. A track-side a monitoring device for rail stress is developed to realize long-term and multi-point measurement. The experimental results also show that the developed rail-stress-monitoring sensor is suitable for measuring rail stress with reliable working performance. A nonlinear model of the CWR 
track on a bridge was developed in [24] for ballasted and non-ballasted tracks. The model and boundary conditions of rail-bridge interaction were calibrated using measured data and code specifications. The model presents an alternative way of modeling the connection between rails and bridge superstructure based on composite materials which can overcome the disadvantages of the spring model. The results of an experimental research activity on the sleeper-ballast resistance along the lateral and the longitudinal directions are reported and discussed in the paper [25]. The strength contributions were identified due to the base, the ballast between the sleepers, and the ballast shoulder to the global resistance of the track in the horizontal plane. The results of this study indicate that the strength percent contributions from the crib, the sleeper base, and the shoulder are, respectively, equal to about 50 , 25 , and $25 \%$ in the lateral direction, and 60, 30, and $10 \%$ in the longitudinal direction. The similar research but with under sleeper pads (UPS) is presented in the experimental investigation [26]. The results show that in compacted ballast conditions the peak lateral resistance due to USPs can increase up to $20 \%$-depending on the material used. The article [27] reviews the last three decades of research and development on the structural analysis and nondestructive evaluation of CWR. Advantages and limitations of the analyzes and of the nondestructive methods are discussed based upon the information available in the scientific literature. An evaluation of the current criteria was performed in [28] using the minimum buckling strength calculation using a developed 3D nonlinear analysis model. The results show that the allowable additional compressive stress was reduced with a comparatively small lateral resistance. The various track conditions were considered. The influence of the longitudinal force in rails in CWR track on the glued insulated rail joints with special fiberglass reinforced synthetic fishplates is presented in the study [29]. The study concludes high resistance of synthetic fishplates.

CWR track stability assessment and monitoring the lateral track geometry is presented in the following studies. The study [30] demonstrates a machine learning-based fault classifier for the condition monitoring of track irregularities in the lateral direction. The classifiers are trained with a dataset composed of numerical simulation results and validated with a dataset of measurements acquired by a diagnostic vehicle on the straight track sections of a highspeed line. The paper shows that application of machine learning methods allows to improve the monitoring results. The study [31] presents a generalization of the artificial intelligence methods for the use in the advance structural health monitoring. The presented concepts are potentially useful for the development of the systems for the track lateral geometry monitoring. The work [32] shows the development of a model-based methodology for the estimation of lateral track irregularities from measurements from different sensors mounted on an in-service vehicle. The proposed methodology is based on the Kalman filtering technique, through the use of a highly simplified linear dynamic model of a bogie, capable of capturing the most relevant lateral dynamic behavior of the entire vehicle. The proposed methodology was experimentally validated through an experimental campaign carried out in a scaled track facility. The paper [33] proposes an inertial monitoring system to detect and estimate track irregularities by using in-service vehicles. The system proposed consists of at least two accelerometers mounted on the bogie axle-box and a GPS. Lateral accelerations have been analyzed to study gauge and lateral alignment deviations and compared with measurements provided by a track monitoring trolley. The paper [34] describes the kinematics used for the calculation of track geometric irregularities of a new Track Geometry Measuring System (TGMS) to be installed in railway vehicles. The TGMS includes a computer for data acquisition and process, a set of sensors including an inertial measuring unit (IMU, 3D gyroscope and 3D accelerometer), two video cameras and an encoder. The TGMS has been experimentally tested in a 1:10 scaled vehicle and track specifically designed for this investigation. The article [35] examines the quality of a specific test section of a railway track from the point of view of the quality of the track geometry. The structure of diagnostic data, the method of their collection, determination of quality indicators, and their evaluation are described. The evaluation of quality indicators is connected with models for predicting the future state of track geometry quality using regression and correlation analysis of the dependence of the development of determining quality indicators on time. A long-term monitoring is presented in [36] as well as numerical analyzes have been performed on the CWR track of a bridge in order to improve the calculation approach for long integral bridges compared to the actual standards. The real deformation behavior of the integral structure as well as the stresses in the continuous welded rail track have been characterized based on the measurement results and compared with the numerical models. The paper [37] presents the finite element model for calculation of rail stresses and displacements due to the temperature changes, which was developed by the authors. The monitoring of the track sections, which are significant regarding traffic safety, was suggested. A non-contacting nondestructive methodology is proposed in [38] for longitudinal stress measurements. The method is based on stereo vision image acquisition and Digital Image Correlation (DIC) for acquiring the full field shape, deformation, and strain measurements taken during a thermal cycle. The paper [39] presents the experimental results obtained in situ 
in full-scale conditions with the Single Tie Push Test and the discrete Cut Panel Pull testing techniques. The differences obtained by performing tests with one, two, and four ties are analyzed with the aim of ensuring a safe evaluation of the main input parameters required for buckling temperatures calculation. It is found that the limit lateral resistance depends neither on the chosen experimental technique, nor on the compaction level of the ballast bed, whereas the peak lateral resistance appears to be dramatically altered if it is evaluated by mean of the Single Tie Push Test. The paper [40] presents an effective analytical method for diagnosing the condition of continuous welded track based on experimental measurements. The method allows for an appropriate repair or maintenance recommendation. Empirical formulas for calculating rail temperature and longitudinal force were derived based on ambient temperature, developed from long-term measurements. An indicator of the second temperature difference railway rails in CWR track is proposed in [41]. The results of the tests confirmed the validity of using the temperature gradient CWR indicator during analyzes and assessments of its condition. The developed indicator is a supplement to the surveying and diagnostic monitoring. The paper [42] presents a methodology for determination of temperature stresses in CWR based on a measurement system for measurement of rail surface temperatures, and coupled transient thermal-stress analysis for simulation of rail temperature field and corresponding stresses. The main advantages of the proposed methodology are high sensitivity to the small temperature variations as well as measurement of single input parameter of rail surface temperature.

The presented review shows that that there are different approaches for the CWR track stability evaluation: from the simplest empirical ones over the analytic to the complicated 3D nonlinear simulations. However, the simple reliable approaches are still used for the practical estimation of the CWR stability. The reviewed monitoring approaches are presented by the cost-expensive track-side systems or the indirect approaches based on the temperature measurements. Thus, the assessment of the condition of the CWR rail of CWR track in the plan still does not have a single and reliable approach, and there are also no methods to determining the possible influence of the irregularities formed during operation in the plan on the indicators characterizing the lateral stability of the CWR track and the temperature regime of the CWR rail (Fig. 1).

\section{Methods and Materials}

The method of monitoring the longitudinal shift of CWR rail and changes in the temperature regime of their operation is based on the method developed by specialists JSC "VNIIZHT" [43]. The essence of this technique is as follows:

(1) Determination of the actual lengthening ( " + ”) or shortening ( " - ") of the CWR rail by the measured displacements of the control sections of the CWR rail relative to the marked sleepers;

(2) Determination of the deviation of the actual fixing temperature from the initial temperature by the formula:

$\Delta t_{\mathrm{ug}}= \pm 85 \Delta l / l$,

where $\Delta l$ is the measured actual lengthening ( " + ") or shortening ( " - ") of the CWR rail, mm; $l$ is the distance between the marked sleepers, $\mathrm{m}$.

For $l=100 \mathrm{~m}$ :

$\Delta t_{\mathrm{ug}}= \pm 0.85 \Delta l$,

3) Determination of the actual temperature of fixing the CWR rail according to the formula:

$t_{o}=t_{z} \pm \Delta t_{u g}$,

where $t_{\mathrm{z}}-$ is the temperature of fixing the CWR rail to a constant mode of operation (during construction, tension discharging, and regulation), ${ }^{\circ} \mathrm{C}$.

4) Verification of the stability condition based on the actual fixing temperature obtained:

$t_{o} \geq \min t_{z . \text { opt }}($ according to the norms $T U-2012[48])$,

$t_{o} \geq \min t_{z}$ (according to the norms $T U-2016[49]$ ),

where: $\min t_{\text {z.opt }}-$ the lower minimum limit of the optimal temperature of fixing the $\mathrm{CWR}$ rail, ${ }^{\circ} \mathrm{C} ; \min t_{\mathrm{Z}}$ - the minimum design temperature of fixing the rail, ${ }^{\circ} \mathrm{C}$, which is determined by the formula:

$\min t_{\mathrm{z}}=t_{\max \cdot \max }-\left[\Delta t_{\mathrm{u}}\right]$,

where: $t_{\max \max }$ - the highest temperature of the rails possible in a particular geographical point, ${ }^{\circ} \mathrm{C} ;\left[\Delta t_{\mathrm{u}}\right]$ - increase in the temperature of the rail, allowed by the condition of stability of the track, ${ }^{\circ} \mathrm{C}$. 


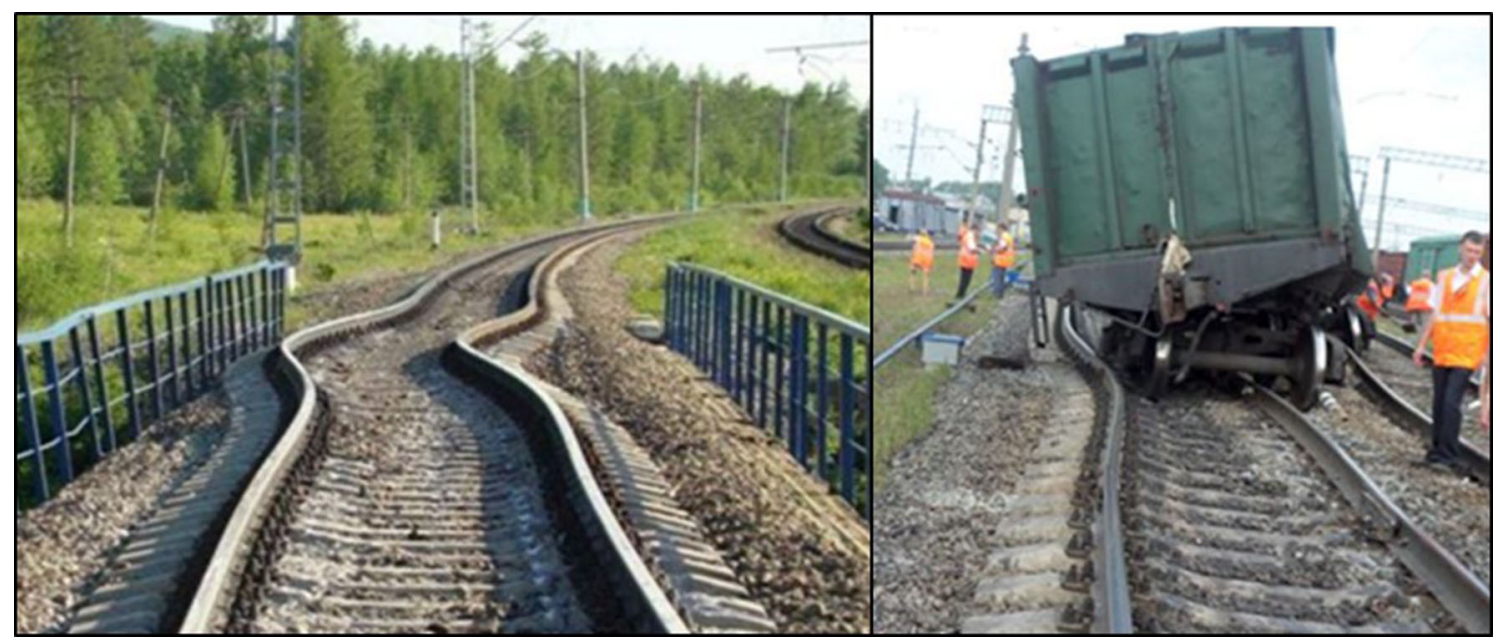

Fig. 1 Track lateral buckling in a curve (left) and under the train loading (right)

5) Making decisions on the need for a maintenance work on the CWR rail.

However, the basic method of VNIIZHT does not take into account the changes of the track state during its lifecycle. The authors of this article have improved the method and proposed a method for determining the conditions and indicators of the lateral stability of a CWR track [44, 45] using the monitoring information. The method allows monitoring and evaluating the condition of the CWR rail of a jointless track in the plan on the basis of indicators characterizing the temperature-stress mode of their operation. The flowchart of the method is presented in Fig. 2.

The main advantages of the developed methodology are:

- The use of data from automated track diagnostics tools that directly describe the actual state of the track [3];

- The ability to evaluate different sections of the track along the length;

- The ability to track the dynamics of the development of indicators that characterize the lateral stability of a jointless track and the temperature mode of operation of CWR rail in time, etc.

The detailed algorithm of the developed technique is as follows:

1) Determination of the temperature equivalent, taking into account the accumulation of irregularities in the plan, according to the formula:

$$
\begin{aligned}
\Delta t_{\mathrm{pl}} & =9360 \cdot K_{\mathrm{ep}} \cdot\left(\rho_{\mathrm{b}}-\rho_{\min }\right)=9360 \cdot K_{\mathrm{ep}} \cdot\left(\rho_{4}-\rho_{20}\right) \\
& =9360 \cdot K_{\mathrm{ep}} \cdot\left(\frac{1}{R_{4}}-\frac{1}{R_{20}}\right),
\end{aligned}
$$

$K_{\text {ep }}$ - the coefficient that depends on the plot of the sleepers and is equal at 1840 sleepers $/ \mathrm{km}, K_{\mathrm{ep}}=0.92$; for 2000 sleepers $/ \mathrm{km}, K_{\text {ep }}=1.0$;

$\rho_{4}$ - the curvature of the track, measured and averaged over a length of $4 \mathrm{~m}, 1 / \mathrm{m}$. The following results were used to justify this length:

- Methods for determining the length of a chord with a lateral irregularity, implemented during the operation of a track measurement car CNII-4, according to which the length of the chord must exceed the length of the specified unevenness by $0,2(20 \%)$ unevenness lengths $l_{\text {unev }}$ on each side, i.e., in total $L_{\text {chord }}=1,4 \cdot l_{\text {unev }}$ (see Table 1).

$\rho_{20}$ - the curvature of the track, measured and averaged over a length of $20 \mathrm{~m}$. The justification of this length is based on a number of experiments conducted by the authors, which allow us to conclude that the length equal to $20 \mathrm{~m}, 1 / \mathrm{m}$ most accurately describes the initial stress state $[2,44,45]$;

$R_{4}$ - the local radius of the curve obtained from the curvature measured and averaged over a length of $4 \mathrm{~m}$ and characterizing the loss of the load-bearing lateral stability of the CWR track during the accumulation of residual track irregularities in the plan, $\mathrm{m}$;

$R_{20}$ - the average radius of the curve obtained from the curvature measured and averaged over a length of $20 \mathrm{~m}$ and characterizing the process of forming the initial stress state of the track, $\mathrm{m}$.

The presented formula (6) is obtained on the basis of the established permissible norms for the temperature increase of CWR rail $\left[\Delta t_{\mathrm{u}}\right]$, which are considered as a function of the radius of the curves $\Delta t_{k . s r}=\Phi\left(\frac{1}{R}\right)$ and are approximated by the equation $\left[\Delta t_{\mathrm{u}}\right]=\left(58-\frac{9360}{R}\right) \cdot K_{\text {ep }}$.

where: 9360 - angular coefficient; 
Fig. 2. The flowchart of determining the conditions and indicators of the lateral stability of a CWR track using monitoring information [46]

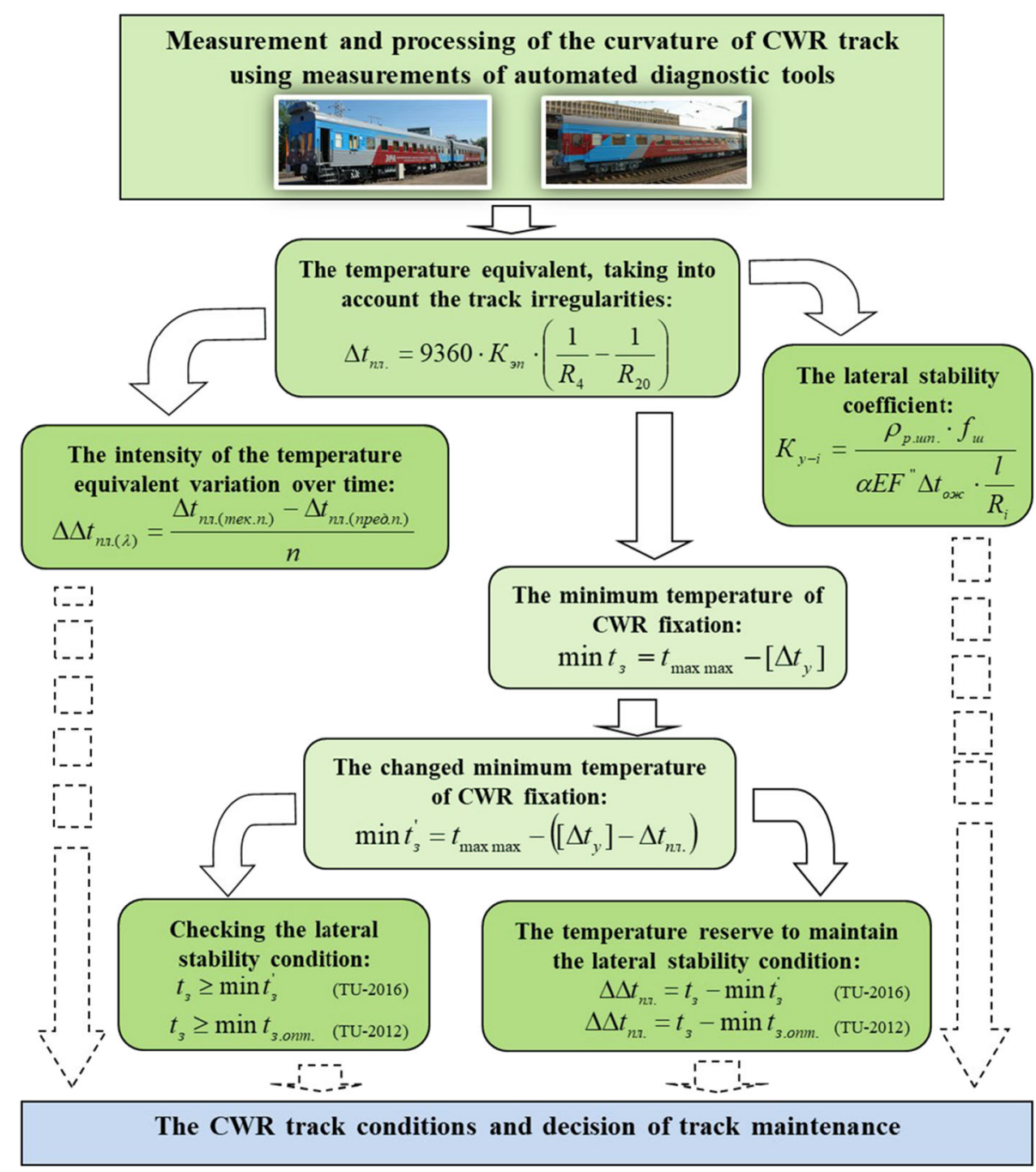

Table 1 Values of the curves chord lengths and radii of the

\begin{tabular}{llllll}
\hline Radius of the curve $R, \mathrm{~m}$ & 600 & 500 & 400 & 300 & Average \\
\hline $\begin{array}{l}\text { Length of the chord for } l_{\text {unev }}, \mathrm{m} \\
\text { Chord length (averaging), } L_{\text {chord }}=\end{array}$ & 3.16 & 3.12 & 2.95 & 2.68 & 2.98 \\
$1,4 \cdot l_{\text {ner, }}, \mathrm{m}$
\end{tabular}

Currently, actual deviations from the norms of track maintenance in the plan are measured by automated track measuring devices and recalculated in the form of deviation of versine $\Delta f$ from the nominal curve versine $f_{\mathrm{n}}$ for the chord $L=20 \mathrm{~m}$. During operation, the curve versine changes from the value $f_{\mathrm{n}}$ to $f_{\max }$. Thus, all changes leading to the appearance of $f_{\max }$, usually originate at chord lengths less than $L=20 \mathrm{~m}$. To solve the problem of controlling the CWR track stability, important is tracking the deviations of the horizontal irregularities over a short track length. Therefore, the chord length of $4 \mathrm{~m}$ is justified and accepted for assessing the temperature-stressed state of CWR, since

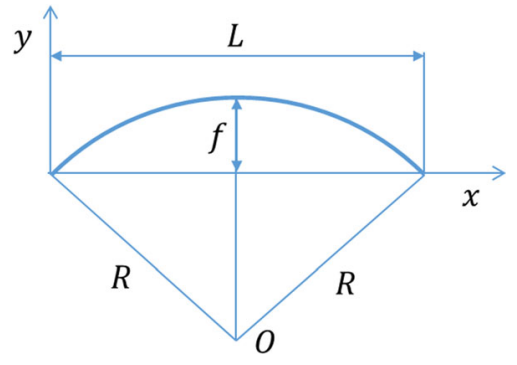

Fig. 3 Curved section of the track: $R$ - curve radius; $L$ - chord; $f-$ versine

it satisfies sections with different radius values. For a curved section of the track, the scheme for determining the versine deviations from is shown in Fig. 3.

The relation of the curve geometrical parameters follows form Fig. 3: 
$R^{2}=\frac{L^{2}}{4}+(R-f)^{2}=\frac{L^{2}}{4}+R^{2}-2 R f+f^{2}$,

Neglecting the small square value $f$ compared to $R$ and $L$ the relation (7) is as follows:

$R=\frac{L^{2}}{8 f}$;

Thus, the radius of the curve depends to a large extent on the length of the chord $L$ and the versine $f$. The radius of the circular curve is a quantity inverse to the curvature of the railway track $\rho=\frac{1}{R}$, which is presented in the equation (6). The equation (6) is obtained based on the fact that during operation, the deviations formed from the standards of maintenance in the plan are manifested through an increase in curvature, which causes a decrease in the base values of the radius of $K_{\mathrm{b}}$ to the minimum values of $R_{\mathrm{min}}$. With such a decrease, the curvature of the track, in contrast to the difference of adjacent bending arrows $\Delta f$ obtained at a chord length of $20 \mathrm{~m}$, can be formed at shorter lengths and carry a greater danger from the point of view of ensuring the lateral stability of the CWR track. In this case, the expected excess of the temperatures of the CWR rail also decreases from $\left[\Delta t_{\mathrm{u}}\right]_{\mathrm{b}}$ to $\left[\Delta t_{\mathrm{u}}\right]_{\min }$ and is equal to:

$\left[\Delta t_{\mathrm{u}}\right]_{b}=\left(58-\frac{9360}{R_{\mathrm{b}}}\right) \cdot K_{\mathrm{ep}}$.

$\left[\Delta t_{\mathrm{u}}\right]_{\min }=\left(58-\frac{9360}{R_{\min }}\right) \cdot K_{\mathrm{ep}}$,

where: $R_{\mathrm{b}}$ - the base radius of the curve, relative to which deviations (irregularities) from the content standards in the plan should be counted, m;

$R_{\min }$ - the minimum radius of the curve that characterizes the local place of increasing the curvature of the track, $\mathrm{m}$;

$\left[\Delta t_{\mathrm{u}}\right]_{b}$ - the expected excess of the temperatures of the CWR rail for $R_{\mathrm{n}},{ }^{\circ} \mathrm{C}$;

$\left[\Delta t_{\mathrm{u}}\right]_{\min }$ - the expected excess of the temperatures of the CWR rail for $R_{\min },{ }^{\circ} \mathrm{C}$;

Deviation of the actual fixing temperature (temperature equivalent) $\Delta t_{\mathrm{pl}}$ for deviations (irregularities) in the plan is determined by the formula:
$\Delta t_{\mathrm{pl}}=\left[\Delta t_{\mathrm{u}}\right]_{b}-\left[\Delta t_{\mathrm{u}}\right]_{\min }$.

Taking into account the formulas (6), the following equations are obtained:

$$
\begin{aligned}
\Delta t_{\mathrm{pl}} & =9360 \cdot K_{\mathrm{ep}} \cdot\left(\frac{1}{R_{\min }}-\frac{1}{R_{\mathrm{b}}}\right) \text { or } \Delta t_{\mathrm{pl}} \\
& =9360 \cdot K_{\mathrm{ep}} \cdot\left(\rho_{\mathrm{b}}-\rho_{\min }\right),
\end{aligned}
$$

where: $\rho_{\mathrm{b}}$ - instantaneous (local) curvature of the track averaged over the base length of the irregularity, $1 / \mathrm{m}$;

$\rho_{\text {min }}$ - instantaneous (local) curvature of the track averaged over the length of a short irregularity, $1 / \mathrm{m}$.

2) Determination of the minimum design temperature of fixing the rail according to the formula (5):

$\min t_{z}=t_{\max \max }-\left[\Delta t_{\mathrm{u}}\right]$

3) Determination of the changed minimum design temperature of fixing the rail according to the formula:

$\min t_{\mathrm{z}}^{\prime}=t_{\max \max }-\left(\left[\Delta t_{u}\right]-\Delta t_{\mathrm{pl}}\right) ;$

4) Checking the stability condition based on the inequality:

$t_{\mathrm{z}} \geq \min t_{\mathrm{z} . \mathrm{opt}}($ according to the norms TU $-2012[48])$,

$t_{\mathrm{z}} \geq \min t_{\mathrm{z}}^{\prime}($ according to the norms $\mathrm{TU}-2016[49]) ;$

5) Determination of the temperature reserve for maintaining the condition of lateral stability of a CWR track by the formula:

$\Delta \Delta t_{\mathrm{pl}}=t_{\mathrm{z}}$ $-\min t_{\text {z.opt }}($ according to the norms TU $-2012[48])$,

(Eq 14.1)

$\Delta \Delta t_{\mathrm{pl}}=t_{\mathrm{z}}-\min t_{\mathrm{z}}^{\prime}($ according to the norms TU $-2016[49])$

(Eq 14.2)

6) Determination of the coefficients of lateral stability of a CWR track in sections with different loads according to the formulas:

Fig. 4 Loading scheme of wheel-rail-sleeper forces

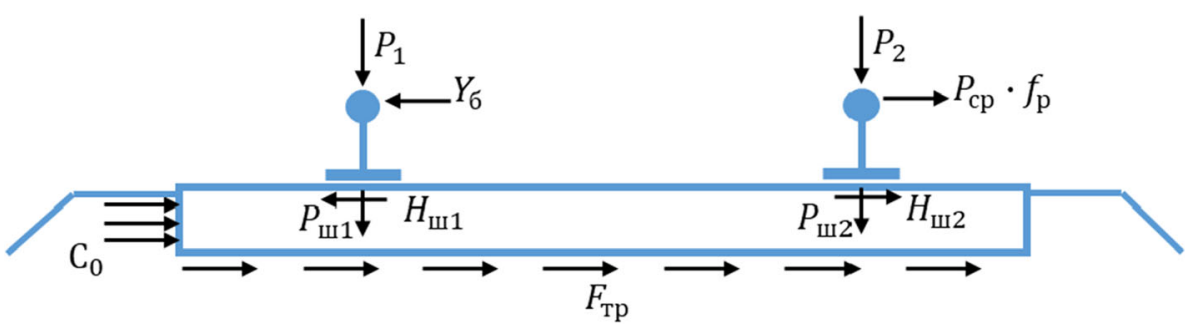




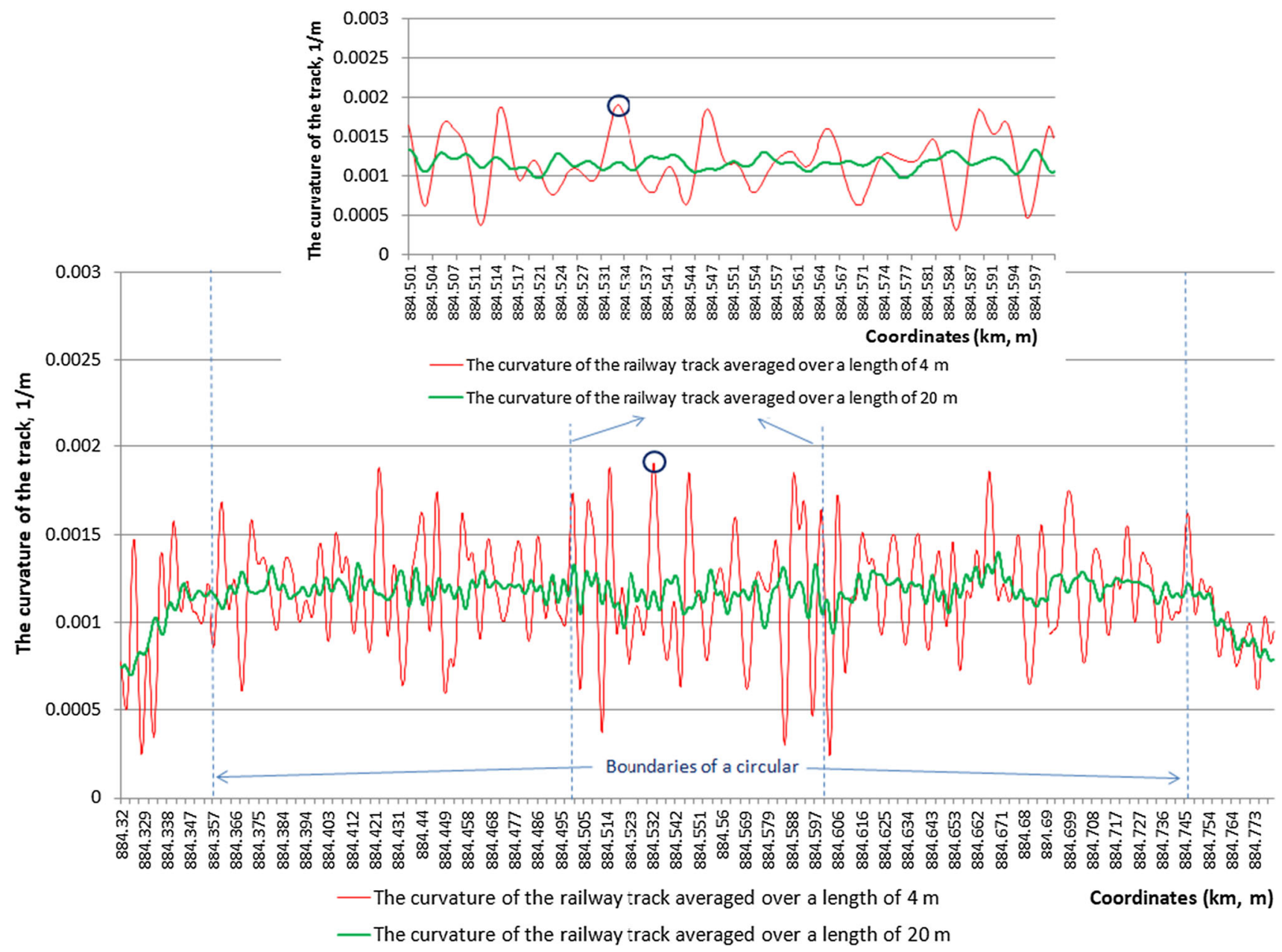

Fig. 5. CWR horizontal curvature averaged over a length of 4 and $20 \mathrm{~m}$ (March 2015)

$K_{u-I}=\frac{\rho_{r . s l} \cdot f_{s l}}{\alpha E F^{\prime \prime} \Delta t_{o z} \cdot \frac{l}{R_{20}}} ;$

$K_{u-I I}=\frac{\rho_{r . s l} \cdot f_{s l}}{\alpha E F^{\prime \prime} \Delta t_{o z} \cdot \frac{l}{R_{4}}} ;$

where $\rho_{\text {r.sl }}-$ the mass of the rail-sleeper grid per sleeper, $\mathrm{kN} /$ sleeper. $\left(\rho_{\text {r.sl }}=3.66 \mathrm{kN} / \mathrm{sleeper}\right)[1,37]$;

$f_{\mathrm{sl}}-$ coefficient of friction sleeper ballast, $f_{\mathrm{sl}}=0.45-$ without taking into account vibration, $f_{s l}=0.37-$ taking into account the vibration [43];

$\alpha$-coefficient of linear expansion of rail steel, $1 / \mathrm{deg}(\alpha$ $=0.00001181 / \mathrm{deg}$ );

$E$ - elastic modulus of rail steel, $\mathrm{kN} / \mathrm{cm}^{2}\left(E=2.1 \cdot 10^{4}\right.$ $\mathrm{kN} / \mathrm{cm}^{2}$ );

$F "$ - cross-sectional area of two rails, $\mathrm{cm}^{2}\left(F^{\prime \prime}=165.13\right.$ $\left.\mathrm{cm}^{2}\right)$

$\Delta t_{\mathrm{oz}}$ - the expected excess of the temperatures of the $\mathrm{CWR}$ rail relative to the initial fixing temperature, ${ }^{\circ} \mathrm{C}$;

$l-$ the distance between the axes of sleepers, $\mathrm{m}(l=0.5$ $\mathrm{m}$ at $R \leq 1200 \mathrm{~m}$ and $l=0.55 \mathrm{~m}$ at $\mathrm{R}>1200 \mathrm{~m})$.

The Eqs 15 and 16 are based on the relation of the resistance and shear loading on one sleeper:

$n=\frac{T_{u d}}{T_{s d v}}$

The sleeper resistance loadings $T_{u d}$ are determined according to the loading scheme Fig. 4, using the following relation:

$T_{u d}=C_{o}+F_{t r}=C_{o}+2 P_{s h} f_{s h}=C_{o}+2 P_{s r} \frac{k_{z} l}{2} f_{s h}$,

where $C_{o}$ - the initial shift resistance of the sleeper without the vertical loading;

$F_{t r}$ - sleeper shift resistance with the vertical loading on the sleeper;

$f_{s h}$ - friction coefficient of the sleeper to the ballast.

The sleeper shear loadings $T_{s d v}$ due to the wheel forces are determined using the following relation: 


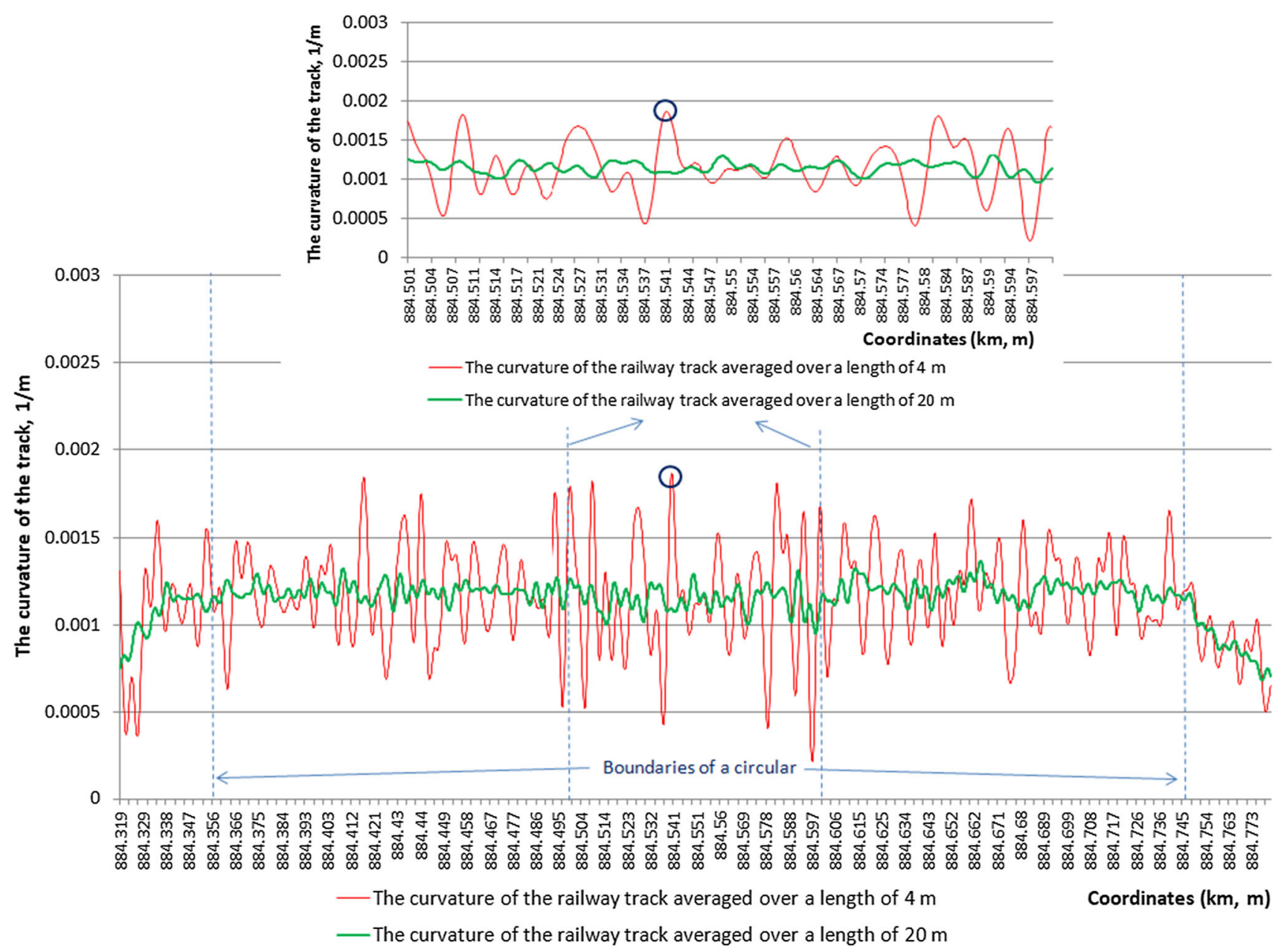

Fig. 6 CWR horizontal curvature averaged over a length of 4 and 20 m (April 2015)

$T_{s d v}=H_{s h}=H_{s h 1}+H_{s h 2}=\left(Y_{b}-P_{s r} \mu_{t r}\right) \frac{k_{z} l}{2}$,

where $H_{s h 1}, H_{s h 2}$ - lateral loadings of the rails on the sleeper;

$P_{s r} \cdot f_{p}$ - lateral loading on the external rail in the curve;

$\frac{k_{z} l}{2}$ - coefficient of one sleeper loading that depends of the track lateral bending stiffness;

$Y_{b}$ - loading on the internal rail of the curve.

7) Determination of the intensity of changes in the temperature equivalent, taking into account the accumulation of irregularities in the plan, over time by the formula [44, 47]:

$\Delta \Delta t_{p l(\lambda)}=\frac{\Delta t_{p l(i)}-\Delta t_{p l(i-1)}}{n}$,

where $\Delta t_{p l(i)}$ - the temperature equivalent of the impact of irregularities in the plan for the current check, ${ }^{\circ} \mathrm{C}$;

$\Delta t_{p l(i-1)}$ - the temperature equivalent of the effect of irregularities in the plan for the previous check, ${ }^{\circ} \mathrm{C}$; $n$ - is the frequency (difference) between checks of the diagnostic tool. If the difference between the checks is 2 weeks, $n=0.5$, if the difference is 1 month, $n=1$, etc.

\section{Case Study of CWR Track Stability Monitoring}

A clear example of identifying places that represent a high probability of loss of lateral stability of a CWR track is the graphs of curvature averaged over a length of 4 and $20 \mathrm{~m}$ for the period March-June 2015 (Figs. 5-8) on one of the sections of the track.

The analysis of the data shown in Figs. 5-8 shows that a significant increase in the curvature of the track within the circular curve on PC6 is observed on the considered section of the track, which indicates the presence of residual deformations in the plan. The most obvious confirmation of the noted deterioration is the dynamics of changes in the lateral stability indicators of the CWR track in the plan, obtained in a curved section of the track with a radius of $R_{\mathrm{p}}$ $=834 \mathrm{~m}$ and shown in Table 2 . 


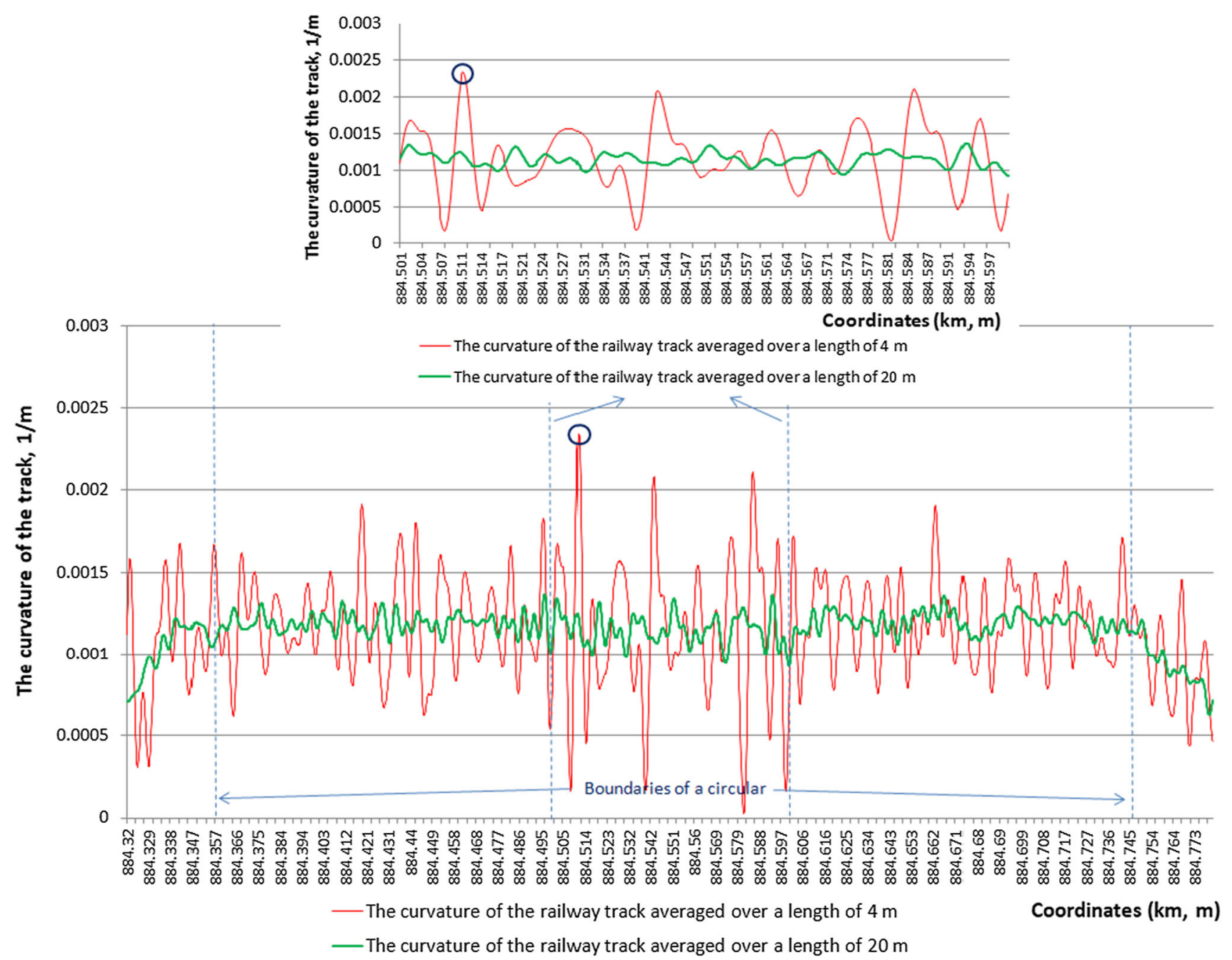

Fig. 7 CWR horizontal curvature averaged over a length of 4 and $20 \mathrm{~m}$ (May 2015)

From the above indicators, which were calculated according to the method described above, it can be seen that from March to June 2015, there was a sharp change in the indicators on the considered section of the track, indicating a loss of lateral stability of the CWR track and a high probability of rolling stock derailment due to ejection due to the presence of deformations in the plan. The described change in the indicators of the state of the jointfree track is most clearly seen in the following graphs:

- Graph of the dynamics of changes in the temperature equivalent (Fig. 9);

- A graph of the intensity of changes in the temperature equivalent over time (Fig. 10) -

- A graph of the dynamics of changes in the coefficients of lateral stability (Fig. 11);

- A graph of the dynamics of changes in the temperature reserve to preserve the condition of lateral stability (Fig. 12).

\section{Discussion}

Analysis of the diagrams 7-10 shows that the state of the CWR track in the plan has changed significantly over the analyzed period of time (March-June 2015) due to the constant growth of irregularities in the plan. Moreover, it can be seen that the most reliable and accurate indicator of places that have a weakening of the transverse stability of a CWR track is the coefficient $K_{\mathrm{u}}\left(R_{4}\right)$, which symbolizes the process of changing the local radius of the curve obtained from the curvature measured and averaged over a length of $4 \mathrm{~m}$. While this cannot be said about the $K_{\mathrm{u}}$ coefficient $\left(R_{20}\right)$. Furthermore, when analyzing the dynamics of changes in both the temperature equivalent itself and the intensity of its change, a constant increase in these indicators is observed, indicating a high probability of violation of the transverse stability of the CWR track (Figs. 5 and 6).

Thus, the developed method and the condition indicator allow to estimate the actual lateral stability of CWR track. 

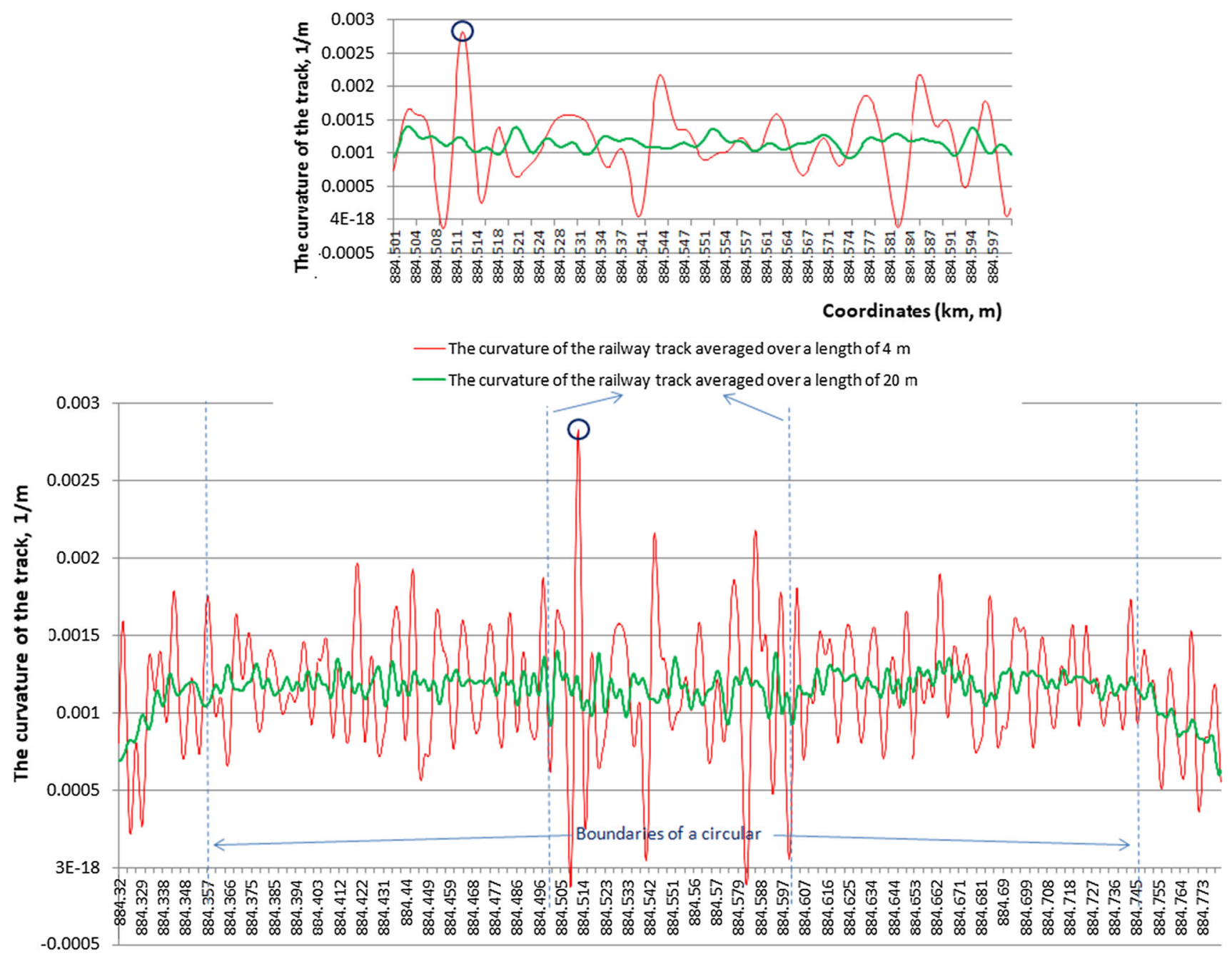

- The curvature of the railway track averaged over a length of $4 \mathrm{~m}$

Coordinates $(\mathrm{km}, \mathrm{m})$

- The curvature of the railway track averaged over a length of $20 \mathrm{~m}$

Fig. 8 CWR horizontal curvature averaged over a length of 4 and $20 \mathrm{~m}$ (June 2015)

Table 2 Dynamics of changes in the indicators of lateral stability of a CWR track

\begin{tabular}{|c|c|c|c|c|c|c|}
\hline $\mathrm{N}^{\mathrm{O}} \Pi / \Pi$ & Indicator & & $\begin{array}{l}\text { March } \\
2015\end{array}$ & $\begin{array}{l}\text { April } \\
2015\end{array}$ & $\begin{array}{l}\text { May } \\
2015\end{array}$ & $\begin{array}{l}\text { June } \\
2015\end{array}$ \\
\hline 1 & The radius obtained from the curvature averaged over a length of $4 \mathrm{~m}$ & $R_{4}, \mathrm{~m}$ & 526 & 535 & 427 & 354 \\
\hline 2 & The radius obtained from the curvature averaged over a length of $20 \mathrm{~m}$ & $R_{20}, \mathrm{~m}$ & 846 & 849 & 850 & 848 \\
\hline 3 & $\begin{array}{l}\text { Temperature equivalent that takes into account the accumulation of } \\
\text { deformations in the plan }\end{array}$ & $\Delta t_{\mathrm{pl}},{ }^{\circ} \mathrm{C}$ & 6.7 & 6.5 & 10.9 & 15.4 \\
\hline 4 & The intensity of the temperature equivalent change over time & $\Delta \Delta t_{\mathrm{pl}(\lambda),}{ }^{\circ} \mathrm{C} /$ period & . & 0.2 & 4.4 & 4.5 \\
\hline 5 & Stability coefficient (at a radius of $R_{4}$ ) & $K_{\mathrm{u}-\mathrm{I}}\left(\mathrm{R}_{4}\right)$ & 1.37 & 1.39 & 1.11 & 0.92 \\
\hline 6 & Stability coefficient (at a radius of $\mathrm{R}_{20}$ ) & $K_{\mathrm{u}-\mathrm{II}}\left(\mathrm{R}_{20}\right)$ & 2.20 & 2.20 & 2.21 & 2.20 \\
\hline 7 & Fixing temperature & $t_{\mathrm{z}},{ }^{\circ} \mathrm{C}$ & 30 & 30 & 30 & 30 \\
\hline 8 & Minimum design fixing temperature & $\min t_{\mathrm{z}},{ }^{\circ} \mathrm{C}$ & 14 & 14 & 14 & 14 \\
\hline 9 & Modified minimum design fixing temperature & $\min \dot{t}_{\mathrm{z}},{ }^{\circ} \mathrm{C}$ & 20.7 & 20.5 & 24.9 & 29.4 \\
\hline 10 & Temperature reserve & $\Delta \Delta t_{\mathrm{pl}},{ }^{\circ} \mathrm{C}$ & 9.3 & 9.5 & 5.1 & 0.6 \\
\hline
\end{tabular}




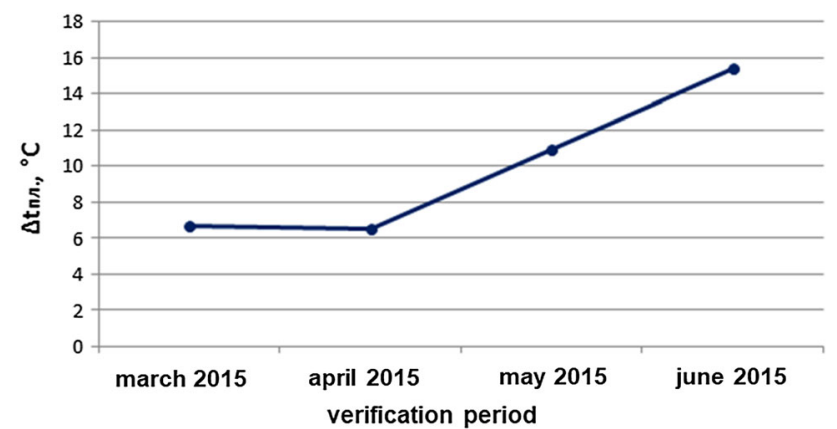

Fig. 9. Dynamics of changes in the temperature equivalent on the considered section of the track

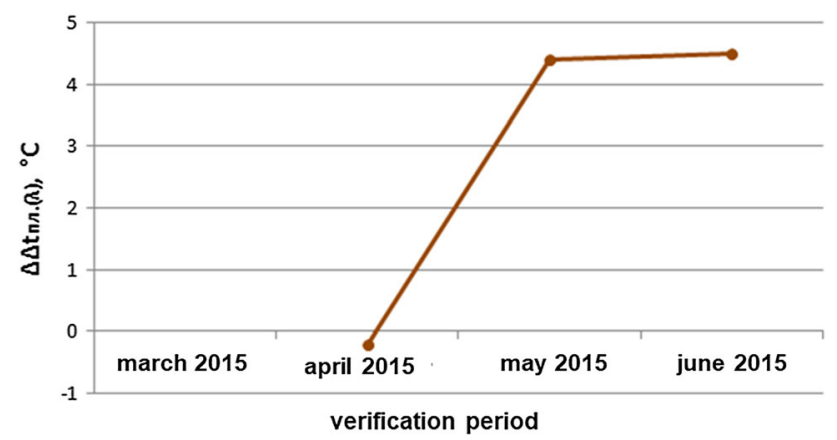

Fig. 10. Intensity of changes in the temperature equivalent over time on the considered section of the track

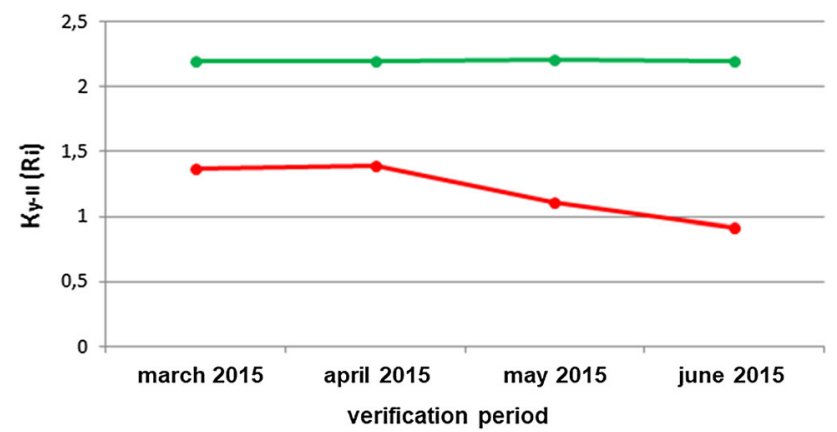

Fig. 11. Dynamics of changes in the coefficients of lateral stability on the considered section of the track

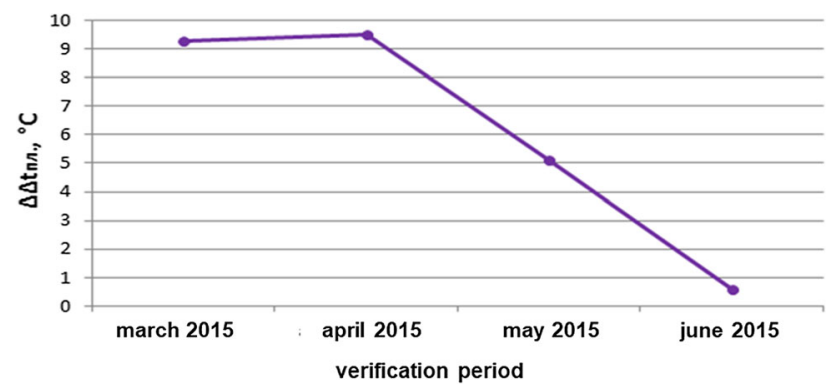

Fig. 12. Dynamics of changes in the temperature reserve for maintaining the condition of lateral stability on the considered section of the track
Nevertheless, the presented method has many shortcomings that could be taken into account in the further studies. The loadings of the specific rolling stock could be considered by multibody modeling like described in $[50,51]$. The condition indicator that is based on the maximal irregularity in one track section cannot describe the condition of whole track curve. However, application of the statistical approach could provide more reliable assessment of the track buckling probability (Table 2).

\section{Conclusion and Subsequent Studies}

The literature review and analysis show that the actual CWR stability monitoring methods are usually based on the limited information about influencing factors like temperature that does not allow to assess the longitudinal forces and track stability. On the other side, the methods for the longitudinal force measurement are not practical for frequent and cost-effective measurement of the whole track lines. Furthermore, no monitoring method consider the geometrical conditions of the CWR track and its evolution.

The paper has presented an experimental study of the CWR track stability monitoring using the information of track measurements cars. The developed methods and algorithms allow, based on these diagnostic tools, to obtain indicators of the transverse stability of a joint-free track on sections of various lengths and to identify places that the greatest danger of violation of lateral stability. The presented case study clearly shows the process of the lateral track geometry accumulation over the long-term period of track operation and the condition indicator provide the assessment of the lateral stability of CWR track.

However, the presented method takes into account the monitoring information of the geometrical irregularity. The further considering the additional monitoring information like the CWR longitudinal shifts would improve the prediction of the lateral stability.

Funding Open Access funding enabled and organized by Projekt DEAL.

Open Access This article is licensed under a Creative Commons Attribution 4.0 International License, which permits use, sharing, adaptation, distribution and reproduction in any medium or format, as long as you give appropriate credit to the original author(s) and the source, provide a link to the Creative Commons licence, and indicate if changes were made. The images or other third party material in this article are included in the article's Creative Commons licence, unless indicated otherwise in a credit line to the material. If material is not included in the article's Creative Commons licence and your intended use is not permitted by statutory regulation or exceeds the permitted use, you will need to obtain permission directly from the copyright holder. To view a copy of this licence, visit http://creativecommons. org/licenses/by/4.0/. 


\section{References}

1. V. Yershov, V. Atapin, On the choice of the temperature of CWR fixing. Путь и путевое хозяйство. - 2015, 6, pp. 18-21. (in Russian)

2. V. Yershov, V. Atapin, Research of the influence of deviations from the norms of content in the plan on the transverse stability of a joinless track. Proceedings of the international scientific and practical conference "Transport-2013". Rostov State University of Railway Transport. - Rostov-on-Don, 2013. - p. 3-5. (in Russian)

3. O. Suslov, Yu. Sedelkin, V. Atapin, Analysis of the stability of a CWR track according to modern diagnostic tools. Путь и путевое хозяйство. 11, 22-28 (2015). ((in Russian))

4. V. Jerschow, A. Bondarenko, U. Gerber, W. Fengler, Einfluss von Schwellenhohllagen auf die Verwerfungssicherheit. ETR. Eisenbahntecnishe Rundschau. 5, 51-54 (2015). ((in German))

5. F. Pospischil, Längsverschweisstes Gleis im engen Bogen: Eine Betrachtung der Gleislagestabilität, Ph.D. Thesis, TU Innsbruck, Austria, 2015 (in German)

6. R. Severin, Lagestabilität lückenloser Meterspurgleise in kleinen Bogenradien, Ph.D. Thesis, ETH Zürich, Switzerland, 2015 (in German). https://doi.org/10.3929/ethz-a-001517517

7. N. Hasan, Threshold radius of a ballasted CWR curved track: Curve classification. J. Transp. Eng. 143(7), 04017026 (2017). https://doi.org/10.1061/JTEPBS.0000054

8. J. Carvalho, J. Delgado, R. Calçada, R. Delgado, A new methodology for evaluating the safe temperature in continuous welded rail tracks. Int. J. Struct. Stab. Dyn. 13(2), 1350016 (2013). https://doi.org/10.1142/S0219455413500168

9. G. Yang, M.A. Bradford, Antisymmetric post-buckling localization of an infinite column on a nonlinear foundation with softening. Int. J. Struct. Stab. Dyn. 15(8), 1540028 (2015). https:// doi.org/10.1142/S0219455415400283

10. H. Papp, N. Liegner, Investigation of internal forces in the rail due to the interaction of CWR tracks and steel railway bridges with ballasted track superstructure. Pollack Periodica. 11(2), 6574 (2016). https://doi.org/10.1556/606.2016.11.2.6

11. J.A. Zakeri, S. Mohammadzadeh, M. Barati, New definition of neutral temperature in continuous welded railway track curves. Periodica Polytech. Civil Eng. 62(1), 143-147 (2018). https://doi. org/10.3311/PPci.8505

12. S.-A. Mosayebi, J.-A. Zakeri, M. Esmaeili, Investigations on vehicle interaction with CWR tracks considering some aspects of rail support modulus. Periodica Polytechnica Civil Eng. 62(2), 444-450 (2018). https://doi.org/10.3311/PPci.10752

13. J.A. Zakeri, M. Barati, Utilizing the track panel displacement method for estimating vertical load effects on the lateral resistance of continuously welded railway track. Proc. Instit. Mech. Eng. Part F J. Rail Rapid Transit. 229(3), 262-267 (2015). https:// doi.org/10.1177/0954409713508937

14. J. Ali Zakeri, M. Esmaeili, A. Kasraei, A. Bakhtiary, A numerical investigation on the lateral resistance of frictional sleepers in ballasted railway tracks. Proc. Instit. Mech. Eng. Part F J. Rail Rapid Transit. 230(2), 440-449 (2014). https://doi.org/10.1177/ 0954409714543507

15. J. Liu, R. Chen, Z. Liu, G. Liu, P. Wang, X. Wei, Comparative analysis of resistance characteristics of composite sleeper and concrete sleeper in ballast bed. Constr. Build. Mater. 300, 124017 (2021). https://doi.org/10.1016/j.conbuildmat.2021.124017

16. Z. Xiong, J. Liu, P. Wang, G. Liu, J. Xiao, S. Yu, Field dynamic performance testing and analysis of polyurethane track and ballasted track in a high-speed railway. J. Civ. Struct. Heal. Monit. 11(4), 867-877 (2021). https://doi.org/10.1007/s13349-02100489-6
17. L.-Y. Shao, M. Zhang, K. Xie, X. Zhang, P. Wang, L. Yan, The longitudinal force measurement of CWR tracks with heterocladding FBG sensors: a proof of concept. Sensors. 16, 2184 (2016). https://doi.org/10.3390/s16122184

18. G.P. Pucillo, Thermal buckling and post-buckling behaviour of continuous welded rail track. Veh. Syst. Dyn. 54(12), 1785-1807 (2016). https://doi.org/10.1080/00423114.2016.1237665

19. G. Yang, M.A. Bradford, Thermal-induced buckling and postbuckling analysis of continuous railway tracks. Int. J. Solids Struct. 97-98, 637-649 (2016). https://doi.org/10.1016/j.ijsolstr. 2016.04.037

20. J. Xiao, H. Liu, P. Wang, G. Liu, J. Xu, R. Chen, Evolution of longitudinal resistance performance of granular ballast track with durable dynamic reciprocated changes. Adv. Mater. Sci. Eng. (2018). https://doi.org/10.1155/2018/3189434

21. D. Zheng, P. Reichl, C. Thompson, Rail buckle early warning detection using in-service instrumented revenue vehicle. ICRT 2017: Railway Development, Operations, and Maintenance Proceedings of the 1st International Conference on Rail Transportation 2017, 2018 pp. 1033-1046. https://doi.org/10.1061/ 9780784481257.103

22. S. Albinovic, S. Dolarevic, D. Marusic, 3D Modeling and nonlinear analysis stability of CWR tracks. Lect. Notes Netw. Syst. 28, 458-469 (2018). https://doi.org/10.1007/978-3-319-71321-2_ 41

23. G. Liu, H. Liu, A. Wei, J. Xiao, P. Wang, S. Li, A new device for stress monitoring in continuously welded rails using bi-directional strain method. J. Mod. Transp. 26(3), 179-188 (2018). https://doi.org/10.1007/s40534-018-0164-Z

24. A. Strauss, M. Šomodíková, D. Lehký, D. Novák, K. Bergmeister, Nonlinear finite element analysis of continuous welded railbridge interaction: monitoring-based calibration. J. Civ. Eng. Manag. 24(4), 344-354 (2018). https://doi.org/10.3846/jcem. 2018.3050

25. A. de Iorio, M. Grasso, F. Penta, G. Pucillo, S. Rossi, M. Testa, On the ballast-sleeper interaction in the longitudinal and lateral directions. Proc. Instit. Mech. Eng. Part F J. Rail Rapid Transit., 2018, 232(2), 620-631. https://doi.org/10.1177/ 0954409716682629

26. G. Pucillo, A. De Iorio, S. Rossi, M. Testa, On the effects of the USP on the lateral resistance of ballasted railway tracks. 2018 Joint Rail Conference, JRC 2018. https://doi.org/10.1115/ JRC2018-6204

27. A. Enshaeian, P. Rizzo, Stability of continuous welded rails: a state-of-the-art review of structural modeling and nondestructive evaluation. Proc. Instit. Mech. Eng. Part F J. Rail Rapid Transit. 2021, Article in Press. https://doi.org/10.1177/ 0954409720986661

28. K.-M. Yun, B.-H. Park, H.-U. Bae, N.-H. Lim, Suggestion for allowable additional compressive stress based on track conditions. Proc. Instit. Mech. Eng. Part F J. Rail Rapid Transit., 2018, 232(5), 1309-1325. https://doi.org/10.1177/0954409717720838

29. A. Németh, S. Fischer, Investigation of glued insulated rail joints with special fiber-glass reinforced synthetic fishplates using in continuously welded tracks. Pollack Periodica. 13(2), 77-86 (2018). https://doi.org/10.1556/606.2018.13.2.8

30. A. De Rosa, R. Kulkarni, A. Qazizadeh, M. Berg, A. Facchinetti, S. Bruni. Monitoring of lateral and cross level track geometry irregularities through onboard vehicle dynamics measurements using machine learning classification algorithms. Proc. Instit. Mech. Eng. Part F J. Rail Rapid Transit., 2021, 235(1), 107-120. https://doi.org/10.1177/0954409720906649

31. D. Luckey, H. Fritz, D. Legatiuk, J.J. Peralta Abadía, C. Walther, K. Smarsly, Explainable Artificial Intelligence to advance structural health monitoring. Struct. Integr. 21, 331-346 (2022). https://doi.org/10.1007/978-3-030-81716-9_16 
32. S. Munoz, J. Ros, P. Urda, J.L. Escalona, Estimation of lateral track irregularity through kalman filtering techniques. IEEE Access. 9(9405673), 60010-60025 (2021). https://doi.org/10. 1016/j.jsv.2021.116122

33. T. Real, J. Montrós, L. Montalbán, C. Zamorano, J.I. Real, Design and validation of a railway inspection system to detect lateral track geometry defects based on axle-box accelerations registered from in-service trains. Journal of Vibroengineering. 16(1), 210-224 (2014)

34. J.L. Escalona, P. Urda, S. Muñoz. A track geometry measuring system based on multibody kinematics, inertial sensors and computer vision. Sensors (Switzerland), 2021, 21(3),683, 1-27. https://doi.org/10.3390/s21030683

35. Šestáková, J., Matejov, A., Pultznerová, A rehabilitation of railway track quality in relation to diagnostic data. Lect. Notes Civil Eng., 2022, 189 LNCE, pp. 197-206. https://doi.org/10.1007/ 978-3-030-86001-1_23

36. M. Wenner, G. Seidl, R. Garn, S. Marx, Long-term structural behaviour of a $170 \mathrm{~m}$ long integral railway bridge - Monitoring and modelling of the soil-structure-CWR interaction. Bautechnik. 96(2), 120-132 (2019)

37. Z., Popović, N., Mirković, L., Brajović, D., Rakic L., Lazarević, S. Petričević, Temperature Stresses in CWR - Experience of Serbian Railways. Adv. Int. Syst. Comput. 2020, 1115 AISC, pp. 825-833. https://doi.org/10.1007/978-3-030-37916-2_81

38. K. Knopf, D. Rizos, Y. Qian, M. Sutton, A stereovision system for rail neutral temperature measurements and effects of the heating method. Proceedings of the 2020 Joint Rail Conference. 2020 Joint Rail Conference. St. Louis, Missouri, USA. April 2022, 2020. V001T08A015. ASME. https://doi.org/10.1115/ JRC2020-8119

39. G. Pucillo, Thermal buckling in cwr tracks: Critical aspects of experimental techniques for lateral track resistance evaluation. 2020 Joint Rail Conference, JRC 2020. https://doi.org/10.1115/ JRC2020-8079

40. J. Kukulski, P. Gołębiowski, J. Makowski, I. Jacyna-Gołda, J. Żak, Effective method for diagnosing continuous welded track condition based on experimental research. Energies. 14(10), 2889 (2021). https://doi.org/10.3390/en14102889

41. A. Kampczyk, K. Dybeł, P. Piotr, The Second Difference in Rail Temperature of Continuous Welded Rail. In book: Proceedings of
IAC 2020 in Budapest. Czech Institute of Academic Education z.s., 2020, pp. 234-248.

42. N. Mirković, L. Brajović, Z. Popović, G. Todorovic, L. Lazarević, M. Petrović, Determination of temperature stresses in CWR based on measured rail surface temperatures. Constr. Build. Mater. 284, 122713 (2021). https://doi.org/10.1016/j. conbuildmat.2021.122713

43. V.G. Albrecht. Longitudinal CWR shift of the railway track and its prevention. Transport, Moscow, 1996. p. 160.

44. V. Yershov, V. Atapin. The method of averaging the curvature in determining the radii of circular curves. Bulletin of Transport of the Volga region. - 2012. No. 5. - pp. 55-59. (in Russian)

45. V. Atapin. An example of the implementation of the methodology for assessing the conditions and the reserve of transverse stability in the curved sections of a joinless track with deviations from the content standards in the plan. Izvestiya Transsib. - 2013. No. 1. - pp. 83-88. (in Russian)

46. V.V. Atapin. Monitoring and assessment of the pre-failure state of the continuous welded track in the plan, PhD thesis, PGUPS, Samara, 2015. (in Russian)

47. V. Yershov, V. Atapin. Investigation of the transverse stability of the curves of the sections of a jointless track. Путь и путевое хозяйство. - 2013. №. 4. - pp. 13-16. (in Russian)

48. TU-2012. Instructions for the construction, installation, maintenance and repair of continuous welded track, approved by the order of JSC "Russian Railways" N 2544 14.12.2016. (in Russian)

49. TU-2016. Instructions for the construction, installation, maintenance and repair of continuous welded track, approved by the order of JSC "Russian Railways" № 2788, 29.12.2012. (in Russian)

50. A.O. Shvets, Analysis of the dynamics of freight cars with lateral displacement of the front bogie. Adv. Math. Models Appl. 6(1), $45-58$ (2021)

51. A.O. Shvets Dynamic interaction of a freight car body and a three-piece bogie during axle load increase. Vehicle Syst. Dyn., 2021. https://doi.org/10.1080/00423114.2021.1942930

Publisher's Note Springer Nature remains neutral with regard to jurisdictional claims in published maps and institutional affiliations. 